\title{
Aspirin Use is Associated With Lower Risk of Barrett's Esophagus in Women
}

\section{Citation}

Jovani, Manol, Yin Cao, Diane Feskanich, David A Drew, Chin Hur, Charles S Fuchs, Brian C Jacobson, and Andrew T Chan. 2017. "Aspirin Use is Associated With Lower Risk of Barrett's Esophagus in Women." Clinical and Translational Gastroenterology 8 (12): e131. doi:10.1038/ ctg.2017.57. http://dx.doi.org/10.1038/ctg.2017.57.

\section{Published Version}

doi:10.1038/ctg.2017.57

\section{Permanent link}

http://nrs.harvard.edu/urn-3:HUL.InstRepos:34868986

\section{Terms of Use}

This article was downloaded from Harvard University's DASH repository, and is made available under the terms and conditions applicable to Other Posted Material, as set forth at http:// nrs.harvard.edu/urn-3:HUL.InstRepos:dash.current.terms-of-use\#LAA

\section{Share Your Story}

The Harvard community has made this article openly available.

Please share how this access benefits you. Submit a story.

\section{Accessibility}




\title{
Aspirin Use is Associated With Lower Risk of Barrett's Esophagus in Women
}

\author{
Manol Jovani, MD, MPH ${ }^{1,2,11}$, Yin Cao, ScD, MPH ${ }^{1,2,3,4,11}$, Diane Feskanich, $\mathrm{ScD}^{5}$, David A. Drew, $\mathrm{PhD}^{1,2}$, Chin Hur, MD, MPH ${ }^{1,2,6}$, \\ Charles S. Fuchs, MD, MPH ${ }^{5,7,8,9}$, Brian C. Jacobson, MD, MPH ${ }^{10,12}$ and Andrew T. Chan, MD, MPH ${ }^{1,2,5,12}$
}

OBJECTIVES: Barrett's esophagus $(B E)$ is the only known precursor to esophageal adenocarcinoma. Data examining the association of aspirin with the onset of $\mathrm{BE}$, particularly for women, are scant and conflicting.

METHODS: We leveraged data from 121,700 women enrolled in the Nurses' Health Study, a large prospective cohort study, who biennially provided detailed information regarding endoscopy and use of aspirin. We used unconditional logistic regression to obtain multivariable (MV)-adjusted odds ratios (ORs) and $95 \%$ confidence intervals (Cl) to estimate the risk of $\mathrm{BE}$ in regular aspirin users ( $\geq 2$ times/week) compared to non-regular users.

RESULTS: Among 27,881 women who had undergone upper Gl endoscopy, we documented 667 BE cases over 18 years of followup. Compared to non-regular users, women who regularly used aspirin had a MV-adjusted OR for BE of $0.85(95 \% \mathrm{Cl:} 0.72,0.99)$. The corresponding OR was $0.73(95 \% \mathrm{Cl}: 0.56,0.96)$ for $\mathrm{BE}$ at least $1 \mathrm{~cm}$ long. Compared with women who did not use any aspirin, the MV-adjusted OR for any $\mathrm{BE}$ was $0.91(95 \% \mathrm{Cl}, 0.69,1.20)$ for women taking $0.5-1.5$ tablets/week; $0.92(95 \% \mathrm{Cl} 0.76,1.11)$ for $2-5$ tablets/week; and $0.71(95 \% \mathrm{Cl} 0.55,0.92)$ for $\geq 6$ tablets/week ( $\mathrm{p}$-trend $=0.01)$. Compared with non-regular users, the MV-adjusted $\mathrm{OR}$ for $\mathrm{BE}$ risk was $0.90(95 \% \mathrm{Cl} 0.67,1.20)$ for women who regularly used aspirin for $1-5$ years, $0.84(95 \% \mathrm{Cl} 0.65,1.09)$ for $6-10$ years, and $0.81(95 \% \mathrm{Cl} 0.67,0.97)$ for $>10$ years $(\mathrm{p}$-trend $=0.03)$.

CONCLUSION: Regular aspirin use was associated with a reduction in the risk of Barrett's esophagus in women. The reduction in risk appeared related to higher dose and longer duration of use.

Clinical and Translational Gastroenterology (2017) 8, e131; doi:10.1038/ctg.2017.57; published online 21 December 2017

Subject Category: Esophagus

\section{INTRODUCTION}

Barrett's esophagus (BE), a condition marked by specialized intestinal metaplasia of the esophageal mucosa in response to gastroesophageal reflux, predisposes to esophageal adenocarcinoma (EAC). ${ }^{1}$ In the US, the incidence of EAC is rising rapidly, ${ }^{2,3}$ and EAC is usually diagnosed at an advanced stage, with 5-year survival of $<20 \%{ }^{4,5} \mathrm{BE}$, the only known precursor of EAC, is also on the rise. ${ }^{1,6}$ Available endoscopic treatments for $\mathrm{BE}$ are costly, sometimes ineffective or may result in significant complications. ${ }^{7-11}$ Thus, there is a need to identify agents that may prevent the onset of $\mathrm{BE}$ and reduce progression to EAC.

Regular aspirin users have a reduced risk of cancer, especially for gastrointestinal (GI) tumors, ${ }^{12,13}$ including EAC. ${ }^{14}$ Observational studies, ${ }^{15-21}$ pooled analyses, ${ }^{22}$ a randomized controlled trial (RCT) ${ }^{23}$ and meta-analyses, ${ }^{24}$ suggest that regular use of non-steroidal anti-inflammatory drugs (NSAIDs), especially aspirin, may prevent the progression from BE to EAC. However, other observational studies $^{25-28}$ and one $\mathrm{RCT}^{29}$ have not observed this association. Practice guidelines do not currently recommend the routine use of aspirin as a chemopreventive agent in patients with BE. ${ }^{7-10}$

Other data suggest that aspirin, but not other NSAIDs, may also inhibit the development of BE. A recent experimental study showed that aspirin interferes directly with nuclear factor kappa light-chain-enhancer of activated B cells (NF-kB) signaling critical to the metaplastic process. ${ }^{30}$ Human data regarding the association of aspirin and $\mathrm{BE}$ development are scant and conflicting, especially for women. Some observational studies, ${ }^{17,31,32}$ but not all, ${ }^{33-36}$ suggest that aspirin, but not NSAIDs, may reduce the onset of BE. Notably, a recent pooled analysis of six studies, which included 1,474 BE patients and 4,274 controls, saw no significant association between aspirin/NSAIDs and BE. ${ }^{36}$ These studies, however, had been limited by a cross-sectional or case-control design,

\footnotetext{
${ }^{1}$ Clinical and Translational Epidemiology Unit, Massachusetts General Hospital and Harvard Medical School, Boston, MA, USA; ${ }^{2}$ Division of Gastroenterology, Massachusetts General Hospital and Harvard Medical School, Boston, MA, USA; ${ }^{3}$ Department of Nutrition, Harvard T. H. Chan School of Public Health, Boston, MA, USA; ${ }^{4}$ Division of Public Health Sciences, Department of Surgery, Washington University in St. Louis, St Louis, MO, USA; ${ }^{5}$ Channing Division of Network Medicine, Department of Medicine, Brigham and Women's Hospital and Harvard Medical School, Boston, MA, USA; ${ }^{\circ}$ Institute for Technology Assessment, Massachusetts General Hospital, Boston, MA, USA; ${ }^{7}$ Medical Yale Cancer Center, New Haven, CT, USA; ${ }^{8}$ Department of Medicine, Yale School of Medicine, New Haven, CT, USA; ${ }^{9}$ Smilow Cancer Hospital, New Haven, CT, USA and ${ }^{10}$ Boston University Medical Center and Boston University School of Medicine, Boston, MA, USA

Correspondence: Andrew T. Chan, MD, MPH, Clinical and Translational Epidemiology Unit, 55 Fruit St, Boston, MA 02114, USA. E-mail: achan@mgh.harvard.edu

${ }^{11}$ Co-first authors.

${ }^{12}$ Co-senior authors.

Received 31 October 2017; accepted 7 November 2017
} 
heterogeneity in the assessment of aspirin exposure, limited information on other key life-style factors for BE, and primarily included men. Because the prevalence of BE is lower and appears later in life among women, ${ }^{37}$ risk factors may differ among women compared with men.

To address these issues, we investigated the association between aspirin/NSAID use and the risk of BE in a large, prospective cohort study comprised exclusively of women.

\section{METHODS}

Study population. We utilized an ongoing prospective study, the Nurses' Health Study (NHS), a cohort of 121,700 female registered nurses, aged 30 to 55 years at enrollment in 1976. Participants mailed follow-up questionnaires every 2 years to provide data on lifestyle factors, medical history and disease outcomes, and every 4 years to report dietary intake. The follow-up rates have been greater than $90 \%$. The institutional review boards of the Harvard T.H. Chan School of Public Health and Partners Healthcare approved the study protocol.

Assessment of regular aspirin/NSAID Use. Aspirin use was first assessed in 1980 and every 2 years thereafter, except in 1986, and the participants were asked whether they took aspirin most weeks, the number of tablets and frequency per week, and years of aspirin usage. Participants were specifically asked about standard-dose (325-mg) aspirin tablets. Between 1994-1998, participants were also asked to convert intake of 4 baby $(81-\mathrm{mg})$ aspirin to 1 standard aspirin tablet $(325 \mathrm{mg})$. Thus, in this paper the term "tablet" represents $325 \mathrm{mg}$ of aspirin achieved through single dose or by taking multiple low-doses. Since 2000, participants were asked to separately report regular use of baby/low-dose aspirin and/or standard-dose aspirin. Consistent with prior studies, ${ }^{12}$ we defined regular aspirin users as those who reported aspirin use at least 2 times per week of either standard or low-dose aspirin at the questionnaire cycle two years prior to index endoscopy. Non-regular users included those who consumed fewer than 2 times per week or no aspirin. The major reported reasons for aspirin/NSAIDs use were headache, arthritis and other musculoskeletal pain, and CVD prevention. ${ }^{38}$ In addition, starting in 1990 and on subsequent questionnaires, we collected updated information on regular use ( $\geq 2$ times/week) of other non-aspirin NSAIDs (including Motrin, Advil, Nuprin, Indocin, Dolobid, Aleve, Naprosyn, Anaprox, Relafen, and Ketoprofen) every two years.

Assessment of other exposures. Weight, menopausal status, use of menopausal hormone therapy, smoking status and history of diabetes and cancer were assessed in 1976 and updated every two years thereafter. We determined body mass index (BMI) from measurements of height provided by participants in 1976 and from measurements of weight updated every two years. Dietary information was first obtained using a semi-quantitative food frequency questionnaire in 1980, updated in 1984, 1986, and every four years thereafter. This permitted calculations of daily caloric and alcohol intakes, and of the Alternative Healthy Eating Index (AHEI)-2010 scores, a measure of overall diet quality described in detail elsewhere. ${ }^{39}$ Physical activity was assessed in 1986, 1988, every 2 years from 1992 to 2000 and every 2 years from 2004 to 2010 . Each activity reported was measured in metabolic equivalent task (MET)-hours per week. One MET represents the energy expended during one hour of rest. Regular use of histamine type 2 receptor antagonists was asked in 1980, 1982, 1994, and every two years thereafter. Regular use of proton pump inhibitors was asked in 2000 and every two years thereafter. In 2002 and 2008, participants were asked about the ever presence of heartburn/acid-reflux one or more times a week, as well as duration and frequency of symptoms. Cigarette use, caloric intake, alcohol use, physical activity, menopausal status and GERD symptoms in this cohort have been validated previously. ${ }^{40-48}$ We used cumulative measures of covariates when appropriate.

Ascertainment of cases and non-cases. Starting in 2002, NHS participants were asked biennially if they had ever undergone esophagogastroduodenoscopy (EGD), the time period of endoscopy, and if they have been diagnosed with $\mathrm{BE}$. We requested written permission to acquire endoscopy and pathology records from women reporting $B E$. Two study physicians (MJ, BCJ), blinded to exposure information, reviewed records to extract information on the initial date of diagnosis of $\mathrm{BE}$, the length of columnar-lined esophagus seen at endoscopy, and the presence or absence of specialized intestinal metaplasia (SIM) documented in biopsies taken from the esophagus.

Our primary outcome was BE of any length, defined by the presence of SIM, according to US guidelines. ${ }^{7,9}$ We also considered secondary outcomes, including 1) a more conservative outcome defined by the presence of SIM and at least $1 \mathrm{~cm}$ of columnar-lined esophagus, according to recent US guidelines, ${ }^{7}$ and 2) a more liberal outcome defined by the presence of any columnar epithelium, with or without SIM, according to UK guidelines, ${ }^{8}$ or a pathology report simply stating "Barrett's esophagus" without a microscopic description. When calculating the mean length of $B E$, reports describing only "tongue(s)" of BE or "short-segment BE" or "irregular Z-lines" were considered to be $0.5 \mathrm{~cm}$ in length.

To verify that blinded review of pathology reports accurately identifies participants with BE, we sought original slides and tissue blocks from health care providers for a subset of NHS participants identified as having SIM by chart review. Upon centralized review of 251 slides in our center by two expert gastrointestinal pathologists, we confirmed SIM in $97 \%$ of instances where the participant was classified as having BE by chart review. When the original histology report only described columnar epithelium in the esophagus, this too was confirmed in $96 \%$ of instances.

Non-cases were defined as participants who reported having undergone EGD but had no diagnosis of BE. We requested written permission to acquire records from 200 randomly-selected women who reported an upper endoscopy, but not $\mathrm{BE}$, to verify that failure to report $\mathrm{BE}$ was a reliable indication that a participant did not have the condition. After 
one mailing attempt, we obtained records from 95 women. In none of these instances did the endoscopist suspect BE. ${ }^{47,48}$

Statistical analysis. We restricted our search to women who reported undergoing EGD between 1992 and 2012 $(n=32,317)$. We excluded women who had missing information about regular aspirin use $(n=2,727)$ and women with history of gastrointestinal cancer prior to their index endoscopy $(n=608)$. To avoid misclassification bias, we also excluded women who reported BE but for whom we could not obtain medical records or for whom the record review failed to support a diagnosis of at least columnar-lined esophagus $(n=1,101)$. The primary study population on which we conducted our analysis was thus comprised of 27,881 women.

For our main analysis, we assessed the association of regular aspirin use ( $\geq 2$ times/week) vs. non-regular use ( $<2$ times/week) and BE of any length. In secondary analyses relating to the outcome, we assessed the association of regular aspirin use with the more conservative $(B E \geq 1 \mathrm{~cm})$ and liberal (any columnar epithelium) definitions. In secondary analyses related to the exposure, we classified women according to aspirin dosage $(0,0.5-1.5,2-5$ and $\geq 6$ tablets per week), and duration (non-regular use (0), 1-5, 6-10 and $>10$ years of regular use). ${ }^{12}$

We used unconditional logistic regression to obtain ageand multivariable (MV)-adjusted odds ratios (ORs) and 95\% confidence intervals (Cls) to estimate the risk of BE. Multivariable models were adjusted for the following potential confounding variables, chosen a priori from the questionnaire cycle two years prior to the index endoscopy: year of endoscopy $^{49,50}$ (continuous), age ${ }^{50,51}$ (continuous), race ${ }^{51,52}$ (white, non-white), BMI ${ }^{45,48}$ ( $<22,22$ to $24.9,25$ to $26.9,27$ to 29.9 and $\geq 30 \mathrm{~kg} / \mathrm{m} 2)$, physical activity ${ }^{53-55}(<1.7,1.7$ to 4.5 , 4.6 to $10.5,10.6$ to 22.1 , and $>22.1$ MET-hours per week), daily caloric intake ${ }^{56-58}$ (kcal/day; continuous), alcohol consumption $^{59-62}(0,0.1$ to $4.9,5.0$ to 15.0 , and $>15 \mathrm{~g} /$ day $)$, menopausal hormone use ${ }^{44,63}$ (premenopausal, never, past, current, dubious/unknown), smoking history ${ }^{47}$ (never, former, current), Alternative Healthy Eating Index (AHEI) score ${ }^{56-58,64}$ (continuous), history of frequent GERD ${ }^{65}$ (yes/no), use of any acid suppressive drugs $^{49}$ (proton pump inhibitors and/or histamine-2 receptor antagonists; yes/no), any non-aspirin NSAID use ${ }^{17}$ (yes/no) and a history of diabetes ${ }^{66,67}$ (yes/no). These variables were chosen to be included in the model as potential confounders of the association between regular aspirin use and BE based on external clinical judgment and previous reports of possible associations with the exposure and the outcome. We assessed linear trend across exposure categories using the median of each category as a continuous variable.

In secondary analyses, we also assessed the association of regular aspirin use and BE among SIM patients without dysplasia, and conducted an analysis limiting the cohort to individuals who reported frequent GERD. Furthermore, we explored potential effect modification by introducing interaction terms between regular aspirin use and all other covariates in the model, and tested for their significance using likelihood ratio tests. Finally, assuming causality, we also calculated the population attributable risk $(95 \% \mathrm{Cl})$, per our previously published methods ${ }^{68}$, to estimate the proportion of BE that would have been prevented in our population if all the participants were regular aspirin users.

All analyses were performed with SAS, version 9.4 (SAS Institute, Cary, North Carolina), with a 2-sided significance $P$-value of $<0.05$.

Table 1 Characteristics $^{\mathrm{a}}$ of the study population of NHS women according to regular $^{\mathrm{b}}$ aspirin use prior to index endoscopy

\begin{tabular}{|c|c|c|}
\hline Characteristics & $\begin{array}{c}\text { Non regular } \\
\text { users } \\
(n=14,419)\end{array}$ & $\begin{array}{c}\text { Regular } \\
\text { users } \\
(n=13,462)\end{array}$ \\
\hline Any columnar epithelium, \% & 2.8 & 2.7 \\
\hline $\mathrm{BE}$ of any length, $\%$ & 2.5 & 2.3 \\
\hline $\mathrm{BE} \geq 1 \mathrm{~cm}, \%$ & 0.9 & 0.7 \\
\hline Mean (SD) BE length ${ }^{\mathrm{C}}, \mathrm{cm}$ & $1.7(2.8)$ & $1.3(1.9)$ \\
\hline Age, years (SD) & $64.4(8.4)$ & $67.6(7.8)$ \\
\hline White race, \% & 97 & 98 \\
\hline \multicolumn{3}{|l|}{ Smoking status } \\
\hline Never, \% & 45 & 44 \\
\hline Past, \% & 47 & 47.5 \\
\hline Current, \% & 8 & 8.5 \\
\hline History of frequent reflux/heartburn ${ }^{d}, \%$ & 39 & 39 \\
\hline \multicolumn{3}{|l|}{ Physical activity ${ }^{\mathbf{e}}$} \\
\hline$<$ 1.7MET-hours/week, \% & 11.5 & 10 \\
\hline 1.7-4.5 MET-hours/week, \% & 15 & 13.5 \\
\hline 4.6-10.5 MET-hours/week, \% & 22 & 22 \\
\hline 10.6-22.1 MET-hours/week, \% & 25.5 & 26 \\
\hline 22.1+ MET-hours/week, \% & 26 & 28 \\
\hline Diabetes, \% & 8 & 12 \\
\hline Regular anti-acid treatment ${ }^{\dagger}, \%$ & 18 & 19 \\
\hline \multicolumn{3}{|l|}{$B M I$} \\
\hline$<22 \mathrm{~kg} / \mathrm{m}^{2}, \%$ & 19 & 17 \\
\hline $22-24.9 \mathrm{~kg} / \mathrm{m}^{2}, \%$ & 32 & 31 \\
\hline $25-26.9 \mathrm{~kg} / \mathrm{m}^{2}, \%$ & 16 & 18 \\
\hline $27-29.9 \mathrm{~kg} / \mathrm{m}^{2}, \%$ & 17 & 17 \\
\hline $30+\mathrm{kg} / \mathrm{m}^{2}, \%$ & 15 & 16.5 \\
\hline Calories consumed/day, kcal & $1705(421)$ & $1722(423)$ \\
\hline AHEl score ${ }^{g}$ & $48(9)$ & $48(9)$ \\
\hline \multicolumn{3}{|l|}{ Alcohol use } \\
\hline$<5$ g/day, $\%$ & 69 & 66.5 \\
\hline $5-9.9 \mathrm{~g} /$ day, \% & 13 & 14 \\
\hline $10-14.9$ g/day, \% & 7 & 8 \\
\hline $15+$ g/day, \% & 10.5 & 11 \\
\hline Non-aspirin NSAID use, $\%$ & 31 & 31 \\
\hline \multicolumn{3}{|l|}{ Menopausal state/hormone use } \\
\hline Pre-menopause, \% & 4 & 3 \\
\hline Never use of hormones, $\%$ & 19 & 18 \\
\hline Past use of hormones, $\%$ & 35 & 37 \\
\hline Current use of hormones, \% & 33 & 33 \\
\hline Unknown use of hormones, \% & 9 & 9 \\
\hline EGD after the year $2002, \%$ & 40 & 45 \\
\hline
\end{tabular}

AHEI: Alternative Healthy Eating Index; BE: Barrett's esophagus; BMI: body mass index; EGD: esophago-gastro-duodenoscopy; NHS: Nurses' Health Study; NSAID: non-steroidal anti-inflammatory drugs.

Values are means(SD) or percentages and are standardized to the age distribution of the study population.

Values of categorical variables may not sum to $100 \%$ due to rounding.

${ }^{a}$ Values calculated from the questionnaire prior to index endoscopy and all values, except age, are age-standardized.

${ }^{b}$ Defined as 2 times/week or more.

${ }^{\mathrm{c} A m o n g}$ participants who had documented length (656 participants), SIM length was slightly higher among non-regular compared to regular aspirin users at univariate $(P=0.03)$ but not multivariable $(P=0.16)$ analysis.

${ }^{\mathrm{d}}$ Defined as symptoms once/week or more.

${ }^{\mathrm{e}}$ Metabolic equivalent task score (mets)/week.

${ }^{f}$ Includes regular use of either histamine type-2 receptor antagonists or protonpump inhibitors.

${ }^{9}$ Score ranges from 0-100, without the alcohol component 


\section{RESULTS}

Participants were mostly Caucasian (97.6\%), with mean (SD) age of $66(S D, 8)$ years, of which $48 \%$ reported regular aspirin use. The characteristics of regular aspirin users at index endoscopy did not differ substantially from those of nonregular users (Table 1). We confirmed pathologically 667 cases of SIM out of 27,881 (2.4\%) women who had undergone at least one EGD. Among these cases of SIM, 225 women (34\%) had a segment $\geq 1 \mathrm{~cm}$ long. An additional 102 cases with either columnar epithelium within the esophagus or simply a pathologist's diagnosis of "Barrett's esophagus" without documentation of SIM were also documented among eligible women (Table 1). Low grade dysplasia (LGD) or high grade dysplasia (HGD) was observed among 28 (4.2\%) participants with SIM of any length, and among $15(6.7 \%)$ and $11(11.1 \%)$ participants with $\mathrm{SIM} \geq 1 \mathrm{~cm}$ and $\geq 3 \mathrm{~cm}$, respectively. Overall, there were 40 cases with suspected dysplasia, of which 20 were in aspirin users (14 LGD, 2 HGD, 4 indefinite for dysplasia) and 20 were in non-aspirin users (8 LGD, 4 HGD, 8 indefinite for dysplasia).

Compared to non-regular users, women who regularly used aspirin had an age-adjusted OR of $0.96(95 \% \mathrm{Cl}$ : $0.82,1.20)$ for risk of BE. However, after multivariable adjustment for known and putative risk factors for $\mathrm{BE}$, regular aspirin use was associated with a statistically significant lower risk (OR 0.85; $95 \% \mathrm{Cl}: 0.72,0.99)$. When restricting the definition of BE to SIM $\geq 1 \mathrm{~cm}$, we observed a somewhat stronger inverse association (OR 0.73; 95\% $\mathrm{Cl}$ : 0.56, 0.96), whereas the association was slightly weaker for BE with or without SIM (OR 0.88; 95\% Cl: 0.76-1.02). For BE with any SIM, the lower risk for regular aspirin users was essentially the same when cases were restricted to those without dysplasia and when the population was restricted to women with frequent GERD symptoms (Table 2). Because acid suppressive drugs is prescribed for reflux symptoms, it is possible for the use of acid suppressive agents to be on the causal pathway between aspirin and BE rather than a confounder. Thus, we repeated our multivariate analysis without additionally adjusting for acid suppressive drugs and found that our results were not substantially different: OR for BE of any length $0.86(95 \% \mathrm{Cl} 0.73,1.00)$ and $\mathrm{OR}$ for $\mathrm{BE} \geq 1 \mathrm{~cm} 0.73(95 \%$ $\mathrm{Cl} 0.56,0.96)$. Additionally, in the main analysis, the effect of regular aspirin use on $\mathrm{BE}$ was not modified by any of the covariates in the model (all $P$-values $>0.13$ ). Finally, we also estimated the population attributable risk of regular aspirin use on $\mathrm{BE}$ assuming a causal relationship. We found that approximately $8 \%(95 \% \mathrm{Cl} 1 \%, 15 \%)$ of $\mathrm{BE}$ of any length could be prevented through regular aspirin use.

In secondary analyses, we further investigated the effect dose and duration on the association of aspirin with BE. The magnitude of the inverse association between aspirin use and BE with any SIM appeared to increase with higher doses ( $p$ trend $=0.01$ ) (Table 3). Compared to women who used zero tablets/week, the multivariable-adjusted OR was $0.91(95 \%$ $\mathrm{Cl}: 0.69,1.20)$ for women taking $0.5-1.5$ tablets/week, 0.92 (95\%Cl: $0.76,1.11)$ for $2-5$ tablets/week, and $0.71(95 \% \mathrm{Cl}$ : $0.55,0.92)$ for women taking $\geq 6$ tablets/week. Risk of BE with $\mathrm{SIM} \geq 1 \mathrm{~cm}$ did not decrease with higher aspirin doses ( $p$-trend $=0.34)$, though statistical power was low to detect a trend.
Table 2 Regular aspirin use and risk of barrett's esophagus in NHS women

\begin{tabular}{|c|c|c|}
\hline & Non-regular users & Regular users ${ }^{a}$ \\
\hline \multicolumn{3}{|l|}{$B E$ of any length } \\
\hline No. cases & 345 & 322 \\
\hline Age-adjusted OR (95\%Cl) & 1 (Reference) & $0.96(0.82,1.12)$ \\
\hline Multivariable OR ${ }^{b}(95 \% \mathrm{Cl})$ & 1 (Reference) & $0.85(0.72,0.99)$ \\
\hline \multicolumn{3}{|l|}{$B E \geq 1 \mathrm{~cm}$} \\
\hline No. cases & 129 & 96 \\
\hline Age-adjusted OR $(95 \% \mathrm{Cl})$ & 1 (Reference) & $0.81(0.62,1.06)$ \\
\hline Multivariable OR ${ }^{\mathrm{b}}(95 \% \mathrm{Cl})$ & 1 (Reference) & 0.56 \\
\hline \multicolumn{3}{|l|}{ BE without Dysplasia } \\
\hline No. cases & 325 & 302 \\
\hline Age-adjusted OR (95\%Cl) & 1 (Reference) & $0.95(0.81,1.12)$ \\
\hline Multivariable $\mathrm{OR}^{\mathrm{b}}(95 \% \mathrm{Cl})$ & 1 (Reference) & $0.84(0.72,0.99)$ \\
\hline \multicolumn{3}{|l|}{ BE only in GERD patients } \\
\hline No. cases & 225 & 201 \\
\hline Age-adjusted OR $(95 \% \mathrm{Cl})$ & 1 (Reference) & $0.91(0.75,1.11)$ \\
\hline Multivariable $\mathrm{OR}^{\mathrm{C}}(95 \% \mathrm{Cl})$ & 1 (Reference) & $0.84(0.69,1.03)$ \\
\hline \multicolumn{3}{|c|}{ Columnar Histology with or without Specialized Intestinal Metaplasia } \\
\hline No. cases & 397 & 372 \\
\hline Age-adjusted OR $(95 \% \mathrm{Cl})$ & 1 (Reference) & $0.98(0.85,1.14)$ \\
\hline Multivariable $\mathrm{OR}^{\mathrm{b}}(95 \% \mathrm{Cl})$ & 1 (Reference) & $0.88(0.76,1.02)$ \\
\hline
\end{tabular}

AHEI: Alternative Healthy Eating Index; BE: Barrett's esophagus; BMI: body mass index; GERD: gastroesophageal reflux disease; NHS: Nurses' Health Study; NSAID: non-steroidal anti-inflammatory drugs; OR: odds ratio.

${ }^{\text {a } D e f i n e d ~ a s ~} 2$ times/week or more.

${ }^{b}$ Multivariable model adjusted for: year of endoscopy (continuous); age (continuous); race (white vs. non-white); physical activity $(<1.7,1.7$ to 4.5 , 4.6 to $10.5,10.6$ to 22.1 , and $>22.1$ metabolic equivalent task score per week); smoking history (never, former, current); caloric intake (kcal/day, continuous); alcohol use $(<5.0,5-15.0$, and $>15 \mathrm{~g} /$ day $)$; menopausal hormone use (premenopausal, never, past, current, dubious/unknown); body mass index $\left(<22,22-24.9,25-26.9,27-29.9\right.$ and $\left.>30 \mathrm{~kg} / \mathrm{m}^{2}\right)$; AHEI score (continuous); history of frequent GERD (yes/no); use of any anti-acid treatment (yes/no); use of any NSAID (yes/no) and a history of diabetes (yes/no).

${ }^{\mathrm{c}}$ Multivariable model adjusted for all of the above except GERD.

The inverse association between aspirin use and BE with any SIM was more evident with increasing duration of use ( $p$ trend $=0.03$ ) (Table 4). Compared to women who were not regular aspirin users, the multivariable-adjusted OR was 0.90 $(95 \% \mathrm{Cl} 0.67,1.20)$ for women who were regular aspirin users for $1-5$ years; $0.84(95 \% \mathrm{Cl} 0.65,1.09)$ for those who used for 6 -10 years; and $0.81(95 \% \mathrm{Cl} 0.67,0.97)$ for women who regularly used aspirin for more than 10 years. As noted for quantity of use, risk of $B E$ with $S I M \geq 1 \mathrm{~cm}$ did not decrease with longer duration of aspirin use ( $p$-trend $=0.22$ ), probably because of low power to detect a trend.

Contrary to our results for aspirin, we observed no association between regular use of other non-aspirin NSAIDs and $\mathrm{BE}$ (OR of $1.05 ; 95 \% \mathrm{Cl}$ : 0.89, 1.25 for any SIM; Table 5).

\section{DISCUSSION}

In this large prospective cohort study of women, we found that regular aspirin use was associated with a significant $15 \%$ lower risk of $\mathrm{BE}$ and a $27 \%$ lower risk of $\mathrm{BE}$ with a length $\geq 1 \mathrm{~cm}$. Risk appeared to decline with increasing dose and duration of aspirin use. In contrast, regular use of any other NSAIDs was not associated with risk of BE. Taken together with data from other studies demonstrating an inverse association between aspirin and EAC and the development of 
dysplasia among patients with $\mathrm{BE}$, these results suggest that aspirin may influence both the initiation and progression of $\mathrm{BE}$.

To our knowledge, this is the first study to explore the association between regular aspirin use and the onset of $\mathrm{BE}$ in a prospective cohort comprised exclusively of women. Our results are consistent with two prior hospital- and population-based retrospective case-control studies which also observed an inverse association between regular aspirin use and BE, especially for higher doses, but not between non-aspirin NSAIDs and BE. ${ }^{31,32}$

In contrast to these results, a recent pooled analysis of data from six case-control studies in the Barrett's and Esophageal Adenocarcinoma Consortium (BEACON), found no association between regular aspirin use and $\mathrm{BE}$ when compared to either population or GERD controls. Similar null findings were reported for non-aspirin NSAIDs and any NSAIDs. ${ }^{36}$ Notably, two of the six individual studies included in the pooled analysis observed an association between aspirin use and $\mathrm{BE} .^{17,32}$ Several differences might serve to explain these conflicting findings, including the case-control design, the heterogeneity of aspirin ascertainment between studies, and inclusion of a predominantly male population. In contrast, our study was nested within a a prospective cohort study of only women. Moreover, our analysis used consistent biennially updated information on aspirin use, minimizing the likelihood of misclassification of exposure which would tend to bias results toward the null. Notably, two of the six individual studies included in the pooled analysis, one of which had nearly $30 \%$ females, observed an association between aspirin use and $B E .^{17,32}$ Because the prevalence of $B E$ is lower in women and appears later in life, ${ }^{37}$ risk factors may differ among women compared with men. Thus, the differing results between our study and the BEACON consortium may reflect a differential effect of aspirin among women compared to men.
An inverse association between aspirin use and BE development is biologically plausible. Barrett's esophagus is thought to arise from inflammation due to chronic tissue injury from reflux of acid into the distal esophagus. ${ }^{1}$ Prostaglandin-endoperoxide synthase (PTGS; also known as cyclooxygenase)-1 and 2, enzymes that mediate inflammation and regulate epithelial cell growth, are believed to play a role in the development of BE since they are overexpressed early in metaplastic tissue, ${ }^{69,70}$ even before any visible evidence of BE. ${ }^{71}$ Animal studies suggest that PTGS-2 inhibition reduces esophagitis and hence the development of columnar epithelium. ${ }^{72}$ By inhibiting PTGS enzymes, thus indirectly reducing cellular proliferation and angiogenesis, aspirin may prevent the onset of $\mathrm{BE}$ and its progression to EAC. ${ }^{17,22,73}$ Such a mechanism is consistent with convincing evidence from cohort studies and RCTs that aspirin reduces the risk of precancerous colorectal adenomas as well as CRC. ${ }^{12,74}$ Consistent with prior retrospective case-control studies, ${ }^{31,32}$ we found that other non-aspirin NSAIDs, which also inhibit PTGS enzymes, were not associated with a reduced risk of BE. This suggests the possibility that aspirin may influence mechanisms of $\mathrm{BE}$ pathogenesis independent of PTGS inhibition. A recent report from Huo et $a{ }^{\beta 0}$ found that esophageal epithelial cells exposed to acid or bile salts leads to activation of NF-kB signaling and expression of caudal-related homeobox transcription factor2 , which plays a key role in the metaplastic process leading to BE. Aspirin, ${ }^{30}$ but not non-aspirin NSAIDs, ${ }^{75}$ can inhibit NF-kB, which may explain the results we observe in this study.

The present study has several strengths, including a large sample size, prospective nature of the study design, and extensive information on known and putative risk factors for BE, and medical record confirmation of reports of $B E$. We also acknowledge some limitations. First, not all endoscopy records had information on BE length. This may lead to sampling error in a minority of cases where for example short-segment BE

Table 3 Dose of aspirin use ${ }^{a}$ and risk of barrett's esophagus in NHS women

\begin{tabular}{|c|c|c|c|c|c|}
\hline & \multicolumn{4}{|c|}{ Tablets/week } & \multirow[b]{2}{*}{ p-trend ${ }^{b}$} \\
\hline & 0 & $0.5-1.5$ & $2-5$ & $\geq 6$ & \\
\hline \multicolumn{6}{|l|}{$B E$ of any length } \\
\hline No. cases & 349 & 64 & 171 & 74 & \\
\hline Age-adjusted OR $(95 \% \mathrm{Cl})$ & 1 (Reference) & $0.84(0.64,1.10)$ & $1.13(0.94,1.37)$ & $0.68(0.53,0.88)$ & 0.006 \\
\hline Multivariable OR ${ }^{\mathrm{c}}(95 \% \mathrm{Cl})$ & 1 (Reference) & $0.91(0.69,1.20)$ & $0.92(0.76,1.11)$ & $0.71(0.55,0.92)$ & 0.01 \\
\hline \multicolumn{6}{|l|}{$B E \geq 1 \mathrm{~cm}$} \\
\hline Nō. cases & 131 & 15 & 44 & 32 & \\
\hline Age-adjusted OR $(95 \% \mathrm{Cl})$ & 1 (Reference) & $0.53(0.31,0.90)$ & $0.83(0.59,1.18)$ & $0.81(0.55,1.20)$ & 0.40 \\
\hline Multivariable OR ${ }^{\mathrm{c}}(95 \% \mathrm{Cl})$ & 1 (Reference) & $0.57(0.33,0.98)$ & $0.72(0.51,1.03)$ & $0.81(0.55,1.20)$ & 0.34 \\
\hline \multicolumn{6}{|c|}{$\begin{array}{l}\text { Columnar Histology with or without Specialized Intestinal } \\
\text { Metaplasia }\end{array}$} \\
\hline No. cases & 406 & 76 & 190 & 92 & \\
\hline Age-adjusted OR (95\%Cl) & 1 (Reference) & $0.86(0.67,1.11)$ & $1.12(0.93,1.33)$ & $0.74(0.59,0.93)$ & 0.02 \\
\hline Multivariable OR $(95 \% \mathrm{Cl})^{\prime}$ & 1 (Reference) & $0.93(0.72,1.20)$ & $0.93(0.77,1.12)$ & $0.76(0.60,0.96)$ & 0.02 \\
\hline
\end{tabular}

AHEI: Alternative Healthy Eating Index; BE: Barrett's esophagus; BMI: body mass index; GERD: gastroesophageal reflux disease; NHS: Nurses' Health Study; NSAID: non-steroidal anti-inflammatory drugs; OR: odds ratio.

aDose of aspirin use two years prior to index endoscopy.

${ }^{\mathrm{b}}$ Tests for trend were conducted using the median value of each category as a continuous variable.

${ }^{\mathrm{C}}$ Multivariable model adjusted for year of endoscopy (continuous); age (continuous); race (white vs. non-white); physical activity ( $<1.7,1.7$ to $4.5,4.6$ to $10.5,10.6$ to 22.1 , and $>22.1$ metabolic equivalent task score per week); smoking history (never, former, current); caloric intake (kcal/day, continuous); alcohol use ( $<5.0,5-15.0$, and $>15 \mathrm{~g} /$ day); menopausal hormone use (premenopausal, never, past, current, dubious/unknown); body mass index ( $<22,22-24.9,25-26.9,27-29.9$ and $>30 \mathrm{~kg} / \mathrm{m}^{2}$ ); AHEI score (continuous); history of frequent GERD (yes/no); use of any anti-acid treatment (yes/no); use of any NSAID (yes/no) and a history of diabetes (yes/no). 


\section{CONFLICT OF INTEREST}

Guarantor of the article: Andrew T. Chan, MD, MPH. Specific author contributions: Study design: Manol Jovani, MD, MPH, Yin Cao, MPH, ScD, Brian C. Jacobson, MD, MPH and Andrew T. Chan, MD, MPH; Data analysis, interpretation of data and drafting of the manuscript. Manol Jovani, MD, MPH, Yin Cao, MPH, ScD and Diane Feskanich, ScD; Interpretation of data and critical revision of the manuscript. all Authors. All Authors approved the final draft submitted. Financial support: This study was supported by the following grants: UM1 CA186107, K24 DK098311, R01DK088782, and by an unrestricted research grant from the Council on Aspirin Health and Prevention. Andrew T. Chan is a Stuart and Suzanne Steele MGH Research Scholar.

Potential competing interests: Andrew T. Chan, MD, MPH previously has served as a consultant for Bayer Healthcare, Pfizer, Inc, and Aralez Pharmaceuticals. This study was not funded by Bayer Healthcare, Pfizer Inc, or Aralez Pharmaceuticals. The remaining authors disclose no conflicts of interest.

Disclaimer: The content is solely the responsibility of the authors and does not necessarily represent the official views of $\mathrm{NIH}$.

\section{ROLE OF THE SPONSORS}

The sponsors had no role in the design and conduct of the study; collection, management, analyses, and interpretation of the data; or preparation, review, or approval of the manuscript. The content is solely the responsibility of the authors and should not be constituted to represent the official views of the National Institute of Diabetes, Digestive and Kidney Diseases or the National Institutes of Health and the Council on Aspirin Health and Prevention.

\section{Publisher's note}

Springer Nature remains neutral with regard to jurisditional claims in published maps and institutional affiliations.

\section{Study Highlights}

\section{WHAT IS CURRENT KNOWLEDGE}

$\checkmark$ Epidemiological studies suggest an inverse association between regular aspirin use and esophageal adenocarcinoma.

$\checkmark$ Data concerning the association between aspirin and Barrett's esophagus are scant and conflicting, especially for women.

\section{WHAT IS NEW HERE}

Regular aspirin use was inversely associated with the risk of Barrett's esophagus in women.

$\checkmark$ This effect appeared to be stronger for higher doses and longer duration.

$\checkmark$ In women, aspirin may be a chemopreventive agent for the earliest stages of the inflammation $>$ metaplasia $>$ adenocarcinoma sequence.

1. Spechler SJ, Souza RF. Barrett's esophagus. N. Engl. J. Med. 2014; 371: 836-845

2. Devesa SS, Blot WJ, Fraumeni JF. Changing patterns in the incidence of esophageal and gastric carcinoma in the United States. Cancer 1998; 83: 2049-2053.
3. Hur C, Miller M, Kong CY et al. Trends in esophageal adenocarcinoma incidence and mortality. Cancer 2013; 119: 1149-1158.

4. Eloubeidi MA, Mason AC, Desmond RA et al. Temporal trends (1973-1997) in survival of patients with esophageal adenocarcinoma in the United States: a glimmer of hope? Am. J. Gastroenterol 2003; 98: 1627-1633.

5. Repici A, Jovani M, Hassan C et al. Management of inoperable malignant oesophageal strictures with fully covered WallFlex $\left({ }^{(}\right)$stent: a multicentre prospective study. Dig. Liver Dis. Off. J. Ital. Soc. Gastroenterol. Ital. Assoc. Study Liver 2014; 46: 1093-1098.

6. Coleman HG, Bhat S, Murray LJ et al. Increasing incidence of Barrett's oesophagus: a population-based study. Eur. J. Epidemiol. 2011; 26: 739-745.

7. Shaheen NJ, Falk GW, Iyer PG et al. ACG Clinical Guideline: Diagnosis and Management of Barrett's Esophagus. Am. J. Gastroenterol. 2016; 111: 30-50 quiz 51.

8. Fitzgerald RC, Pietro M, di, Ragunath K et al. British Society of Gastroenterology guidelines on the diagnosis and management of Barrett's oesophagus. Gut 2014; 63: 7-42.

9. American Gastroenterological Association, Spechler SJ, Sharma P et al. American Gastroenterological Association medical position statement on the management of Barrett's esophagus. Gastroenterology 2011; 140: 1084-1091.

10. Whiteman DC, Appleyard M, Bahin FF et al. Australian clinical practice guidelines for the diagnosis and management of Barrett's esophagus and early esophageal adenocarcinoma. J. Gastroenterol. Hepatol. 2015; 30: 804-820.

11. Jovani M, Wallace M. Is complete endoscopic resection still a viable option for Barrett'srelated dysplasia and neoplasia? Clin. Gastroenterol. Hepatol. Off. Clin. Pract. J. Am Gastroenterol. Assoc 2014; 12: 2011-2014.

12. Cao $\mathrm{Y}$, Nishihara $\mathrm{R}$, Wu $\mathrm{K}$ et al. Population-wide Impact of Long-term Use of Aspirin and the Risk for Cancer. JAMA Oncol 2016; 2: 762-769.

13. Cuzick J, Thorat MA, Bosetti $C$ et al. Estimates of benefits and harms of prophylactic use of aspirin in the general population. Ann. Oncol. Off. J. Eur. Soc. Med. Oncol. 2015; 26 : 47-57.

14. Corley DA, Kerlikowske K, Verma R et al. Protective association of aspirin/NSAIDs and esophageal cancer: a systematic review and meta-analysis. Gastroenterology 2003; 124: 47-56.

15. Tsibouris $P$, Hendrickse MT, Isaacs PET. Daily use of non-steroidal anti-inflammatory drugs is less frequent in patients with Barrett's oesophagus who develop an oesophageal adenocarcinoma. Aliment. Pharmacol. Ther. 2004; 20: 645-655.

16. Vaughan TL, Dong LM, Blount PL et al. Non-steroidal anti-inflammatory drugs and risk of neoplastic progression in Barrett's oesophagus: a prospective study. Lancet Oncol. 2005; 6 : 945-952.

17. Anderson LA, Johnston BT, Watson RGP et al. Nonsteroidal anti-inflammatory drugs and the esophageal inflammation-metaplasia-adenocarcinoma sequence. Cancer Res. 2006; 66 : 4975-4982.

18. Nguyen DM, Richardson P, El-Serag HB. Medications (NSAIDs, statins, proton pump inhibitors) and the risk of esophageal adenocarcinoma in patients with Barrett's esophagus. Gastroenterology 2010; 138: 2260-2266.

19. Kantor ED, Onstad L, Blount PL et al. Use of statin medications and risk of esophagea adenocarcinoma in persons with Barrett's esophagus. Cancer Epidemiol. Biomark. Prev. Publ. Am. Assoc. Cancer Res. Cosponsored Am. Soc. Prev. Oncol 2012; 21: 456-461.

20. Beales ILP, Vardi I, Dearman L. Regular statin and aspirin use in patients with Barrett's oesophagus is associated with a reduced incidence of oesophageal adenocarcinoma. Eur. J. Gastroenterol. Hepatol. 2012; 24: 917-923.

21. Kastelein F, Spaander MCW, Biermann $\mathrm{K}$ et al. Nonsteroidal anti-inflammatory drugs and statins have chemopreventative effects in patients with Barrett's esophagus. Gastroenterology 2011; 141: 2000-2008 quiz e13-14.

22. Liao LM, Vaughan TL, Corley DA et al. Nonsteroidal anti-inflammatory drug use reduces risk of adenocarcinomas of the esophagus and esophagogastric junction in a pooled analysis. Gastroenterology 2012; 142: 442-452.e5 quiz e22-23.

23. Falk GW, Buttar NS, Foster NR et al. A combination of esomeprazole and aspirin reduces tissue concentrations of prostaglandin $E(2)$ in patients with Barrett's esophagus. Gastroenterology 2012; 143: 917-926.e1.

24. Zhang $\mathrm{S}$, Zhang X-Q, Ding X-W et al. Cyclooxygenase inhibitors use is associated with reduced risk of esophageal adenocarcinoma in patients with Barrett's esophagus: a metaanalysis. Br. J. Cancer 2014; 110: 2378-2388.

25. Masclee GMC, Coloma PM, Spaander MCW et al. NSAIDs, statins, low-dose aspirin and PPIs, and the risk of oesophageal adenocarcinoma among patients with Barrett's oesophagus: a population-based case-control study. BMJ Open 2015; 5: e006640.

26. Bani-Hani KE, Bani-Hani BK, Martin IG. Characteristics of patients with columnar-lined Barrett's esophagus and risk factors for progression to esophageal adenocarcinoma. World J. Gastroenterol. 2005; 11: 6807-6814.

27. Gatenby PA, Ramus JR, Caygill CP et al. Aspirin is not chemoprotective for Barrett's adenocarcinoma of the oesophagus in multicentre cohort. Eur. J. Cancer Prev. Off. J. Eur. Cancer Prev. Organ. ECP 2009; 18: 381-384.

28. Nguyen DM, El-Serag HB, Henderson $L$ et al. Medication usage and the risk of neoplasia in patients with Barrett's esophagus. Clin. Gastroenterol. Hepatol. Off. Clin. Pract. J. Am. Gastroenterol. Assoc 2009; 7: 1299-1304.

29. Heath El, Canto Ml, Piantadosi S et al. Secondary chemoprevention of Barrett's esophagus with celecoxib: results of a randomized trial. J. Natl. Cancer Inst. 2007; 99: 545-557.

30. Huo X, Zhang X, Yu $C$ et al. Aspirin prevents NF-kB activation and CDX2 expression stimulated by acid and bile salts in oesophageal squamous cells of patients with Barrett's 
oesophagus. Gut 2017; pii: gutinl-2016-313584; doi: 10.1136/qutjnl-2016-313584 [e-pub ahead of print 25 April 2017].

31. Omer ZB, Ananthakrishnan AN, Nattinger KJ et al. Aspirin protects against Barrett's esophagus in a multivariate logistic regression analysis. Clin. Gastroenterol. Hepatol. Off. Clin. Pract. J. Am. Gastroenterol. Assoc 2012; 10: 722-727.

32. Schneider JL, Zhao WK, Corley DA. Aspirin and nonsteroidal anti-inflammatory drug use and the risk of Barrett's esophagus. Dig. Dis. Sci. 2015; 60: 436-443.

33. Thrift AP, Pandeya N, Smith KJ et al. The use of nonsteroidal anti-inflammatory drugs and the risk of Barrett's oesophagus. Aliment. Pharmacol. Ther. 2011; 34: 1235-1244.

34. Khalaf N, Nguyen T, Ramsey D et al. Nonsteroidal anti-inflammatory drugs and the risk of Barrett's esophagus. Clin. Gastroenterol. Hepatol. Off. Clin. Pract. J. Am. Gastroenterol. Assoc 2014; 12: 1832-1839.e6.

35. Goldberg A, Gerkin RD, Young M. Medical Prevention of Barrett's Esophagus: Effects of Statins, Aspirin, Non-aspirin NSAIDs, Calcium, and Multivitamins. Dig. Dis. Sci. 2015; 60 : 2058-2062.

36. Thrift AP, Anderson LA, Murray LJ et al. Nonsteroidal Anti-Inflammatory Drug Use is Not Associated With Reduced Risk of Barrett's Esophagus. Am. J. Gastroenterol. 2016; 111 1528-1535.

37. Runge TM, Abrams JA, Shaheen NJ. Epidemiology of Barrett's Esophagus and Esophageal Adenocarcinoma. Gastroenterol. Clin. North Am. 2015; 44: 203-231.

38. Manson JE, Stampfer MJ, Colditz GA et al. A prospective study of aspirin use and primary prevention of cardiovascular disease in women. JAMA 1991; 266: 521-527.

39. Chiuve SE, Fung TT, Rimm EB et al. Alternative dietary indices both strongly predict risk of chronic disease. J. Nutr. 2012; 142: 1009-1018.

40. Al-Delaimy WK, Willett WC. Measurement of tobacco smoke exposure: comparison of toenail nicotine biomarkers and self-reports. Cancer Epidemiol. Biomark. Prev. Publ. Am. Assoc. Cancer Res. Cosponsored Am. Soc. Prev. Oncol 2008; 17: 1255-1261.

41. Colditz GA, Stampfer MJ, Willett WC et al. Reproducibility and validity of self-reported menopausal status in a prospective cohort study. Am. J. Epidemiol. 1987; 126: 319-325.

42. Willett WC, Sampson L, Stampfer MJ et al. Reproducibility and validity of a semiquantitative food frequency questionnaire. Am. J. Epidemiol. 1985; 122: 51-65.

43. Wolf AM, Hunter DJ, Colditz GA et al. Reproducibility and validity of a self-administered physical activity questionnaire. Int. J. Epidemiol. 1994; 23: 991-999.

44. Jacobson BC, Moy B, Colditz GA et al. Postmenopausal hormone use and symptoms of gastroesophageal reflux. Arch. Intern. Med. 2008; 168: 1798-1804.

45. Jacobson BC, Somers SC, Fuchs CS et al. Body-mass index and symptoms of gastroesophageal reflux in women. N. Engl. J. Med. 2006; 354: 2340-2348.

46. Rimm EB, Stampfer MJ, Colditz GA et al. Validity of self-reported waist and hip circumferences in men and women. Epidemiol. Camb. Mass 1990; 1: 466-473.

47. Jacobson BC, Giovannucci EL, Fuchs CS. Smoking and Barrett's esophagus in women who undergo upper endoscopy. Dig. Dis. Sci. 2011; 56: 1707-1717.

48. Jacobson BC, Chan AT, Giovannucci EL et al. Body mass index and Barrett's oesophagus in women. Gut 2009; 58: 1460-1466.

49. El-Serag HB, Aguirre T, Kuebeler $M$ et al. The length of newly diagnosed Barrett's oesophagus and prior use of acid suppressive therapy. Aliment. Pharmacol. Ther. 2004; 19: 1255-1260.

50. Blankenstein M, van, Looman CWN, Johnston BJ et al. Age and sex distribution of the prevalence of Barrett's esophagus found in a primary referral endoscopy center. Am. J. Gastroenterol. 2005; 100: 568-576.

51. Rubenstein JH, Mattek N, Eisen G. Age- and sex-specific yield of Barrett's esophagus by endoscopy indication. Gastrointest. Endosc. 2010; 71: 21-27.

52. Corley DA, Kubo A, Levin TR et al. Race, ethnicity, sex and temporal differences in Barrett's oesophagus diagnosis: a large community-based study, 1994-2006. Gut2009; 58: 182-188.

53. Rubenstein JH, Chen JW. Epidemiology of gastroesophageal reflux disease. Gastroenterol. Clin. North Am. 2014; 43: 1-14.

54. Singh S, Devanna S, Edakkanambeth Varayil J et al. Physical activity is associated with reduced risk of esophageal cancer, particularly esophageal adenocarcinoma: a systematic review and meta-analysis. BMC Gastroenterol 2014; 14: 101.

55. Hilal J, El-Serag HB, Ramsey D et al. Physical activity and the risk of Barrett's esophagus. Dis. Esophagus Off. J. Int. Soc. Dis. Esophagus 2016; 29: 248-254.

56. Kubo A, Corley DA, Jensen CD et al. Dietary factors and the risks of oesophageal adenocarcinoma and Barrett's oesophagus. Nutr. Res. Rev. 2010; 23: 230-246.

57. O'Doherty MG, Cantwell MM, Murray LJ et al. Dietary fat and meat intakes and risk of reflux esophagitis, Barrett's esophagus and esophageal adenocarcinoma. Int. J. Cancer 2011; 129: 1493-1502.

58. Kubo A, Levin TR, Block $G$ et al. Dietary patterns and the risk of Barrett's esophagus. Am. J. Epidemiol. 2008; 167: 839-846.

59. Ren L-L, Yan T-T, Wang Z-H et al. Alcohol consumption and the risk of Barrett's esophagus: a comprehensive meta-analysis. Sci. Rep 2015; 5: 16048.
60. Matsuzaki J, Suzuki H, Kobayakawa M et al. Association of Visceral Fat Area, Smoking, and Alcohol Consumption with Reflux Esophagitis and Barrett's Esophagus in Japan. PloS One 2015; 10: e0133865.

61. Xu Q, Guo W, Shi X et al. Association Between Alcohol Consumption and the Risk of Barrett's Esophagus: A Meta-Analysis of Observational Studies. Medicine (Baltimore) 2015; 94: e1244.

62. Kubo A, Levin TR, Block G et al. Alcohol types and sociodemographic characteristics as risk factors for Barrett's esophagus. Gastroenterology 2009; 136: 806-815.

63. Menon S, Nightingale P, Trudgill N. Is hormone replacement therapy in post-menopausal women associated with a reduced risk of oesophageal cancer? United Eur. Gastroenterol. J. 2014: 2: 374-382.

64. Onvani S, Haghighatdoost F, Surkan PJ et al. Adherence to the Healthy Eating Index and Alternative Healthy Eating Index dietary patterns and mortality from all causes, cardiovascular disease and cancer: a meta-analysis of observational studies. J. Hum. Nutr. Diet. Off. J. Br. Diet. Assoc 2017; 30: 216-226.

65. Thrift AP, Kramer JR, Qureshi Z et al. Age at onset of GERD symptoms predicts risk of Barrett's esophagus. Am. J. Gastroenterol. 2013; 108: 915-922.

66. Iyer PG, Borah BJ, Heien HC et al. Association of Barrett's esophagus with type II Diabetes Mellitus: results from a large population-based case-control study. Clin. Gastroenterol. Hepatol. Off. Clin. Pract. J. Am. Gastroenterol. Assoc 2013; 11: 1108-1114.e5.

67. He Q, Li J-D, Huang W et al. Metabolic syndrome is associated with increased risk of Barrett esophagus: A meta-analysis. Medicine (Baltimore) 2016; 95: e4338.

68. Spiegelman D, Hertzmark E, Wand HC. Point and interval estimates of partial population attributable risks in cohort studies: examples and software. Cancer Causes Control CCC 2007: 18: 571-579.

69. Shirvani VN, Ouatu-Lascar R, Kaur BS et al. Cyclooxygenase 2 expression in Barrett's esophagus and adenocarcinoma: Ex vivo induction by bile salts and acid exposure. Gastroenterology 2000; 118: 487-496.

70. Lagorce C, Paraf F, Vidaud D et al. Cyclooxygenase-2 is expressed frequently and early in Barrett's oesophagus and associated adenocarcinoma. Histopathology 2003; 42: 457-465.

71. Hamoui N, Peters JH, Schneider S et al. Increased acid exposure in patients with gastroesophageal reflux disease influences cyclooxygenase-2 gene expression in the squamous epithelium of the lower esophagus. Arch. Surg. Chic. III 1960 2004; 139: 712-716 discussion 716-717.

72. Oyama K, Fujimura T, Ninomiya I et al. A COX-2 inhibitor prevents the esophageal inflammation-metaplasia-adenocarcinoma sequence in rats. Carcinogenesis 2005; 26: 565-570.

73. Piazuelo E, Jimenez P, Lanas A. COX-2 inhibition in esophagitis, Barrett's esophagus and esophageal cancer. Curr. Pharm. Des 2003; 9: 2267-2280.

74. Chan AT, Arber N, Burn J et al. Aspirin in the chemoprevention of colorectal neoplasia: an overview. Cancer Prev. Res. Phila. Pa 2012; 5: 164-178.

75. Yin MJ, Yamamoto Y, Gaynor RB. The anti-inflammatory agents aspirin and salicylate inhibit the activity of I(kappa)B kinase-beta. Nature 1998; 396: 77-80.

76. Dam RM, van, Li T, Spiegelman D et al. Combined impact of lifestyle factors on mortality: prospective cohort study in US women. BMJ 2008; 337: a1440.

77. Sarna L, Bialous SA, Cooley ME et al. Impact of smoking and smoking cessation on healthrelated quality of life in women in the Nurses' Health Study. Qual. Life Res. Int. J. Qual. Life Asp. Treat. Care Rehabil 2008; 17: 1217-1227.

78. Ajani UA, Ford ES, Greenland KJ et al. Aspirin use among U.S. adults: Behavioral Risk Factor Surveillance System. Am. J. Prev. Med. 2006; 30: 74-77.

cc) (1) (8) $\odot$ Clinical and Translational Gastroenterology is an openaccess journal published by Nature Publishing Group. This work is licensed under a Creative Commons AttributionNonCommercial-NoDerivs 4.0 International License. The images or other third party material in this article are included in the article's Creative Commons license, unless indicated otherwise in the credit line; if the material is not included under the Creative Commons license, users will need to obtain permission from the license holder to reproduce the material. To view a copy of this license, visit http:// creativecommons.org/licenses/by-nc-nd/4.0/

(C) The Author(s) 2017 